\title{
Observation and Numerical Simulation of Terrain-Induced Windshear at the Hong Kong International Airport in a Planetary Boundary Layer without Temperature Inversions
}

\author{
P. W. Chan and K. K. Hon \\ Hong Kong Observatory, Hong Kong \\ Correspondence should be addressed to P. W. Chan; pwchan@hko.gov.hk
}

Received 25 September 2015; Revised 5 January 2016; Accepted 12 January 2016

Academic Editor: Anthony R. Lupo

Copyright ( $\odot 2016$ P. W. Chan and K. K. Hon. This is an open access article distributed under the Creative Commons Attribution License, which permits unrestricted use, distribution, and reproduction in any medium, provided the original work is properly cited.

\begin{abstract}
Terrain-induced windshear at Hong Kong International Airport (HKIA) could be hazardous to the landing and departing aircraft. Such windshear occurring in a planetary boundary layer without temperature inversions is studied in this paper by using the data from the Terminal Doppler Weather Radar and Light Detection and Ranging systems. A high resolution numerical model, called aviation model (AVM), is also employed to find out its capability to forecast the occurrence of such windshear. The model is found to have skills in capturing the terrain-induced windshear, including the terrain-induced microburst due to the mountains of Lantau Island. Moreover, the windshear detection algorithm as applied to the AVM output, called AVM-GLYGA, is able to give advance alert for the occurrence of low-level windshear. The model also offers new dataset, such as vertical velocity and vertical cross sections across the windshear feature, to study the terrain-induced windshear phenomena with new insights. The AVM is found to have good skills in depicting the terrain-disrupted airflow at the airport area, and more comprehensive study would be conducted to study the skills of AVM-GLYGA as compared with pilot windshear report as sky truth.
\end{abstract}

\section{Introduction}

The Hong Kong International Airport (HKIA) is situated in an area of complex terrain. To the south of the airport, there is the mountainous Lantau Island with peaks rising to about $1 \mathrm{~km}$ above mean sea level (amsl) with valleys as low as $400 \mathrm{~m}$ amsl in between. When winds blow from east through southeast to southwest, there could be terraininduced airflow disturbances that may affect the operation of the aircraft at HKIA. They may take the form of significant low-level windshear, which means a headwind/tailwind (i.e., wind component along the runway orientation) change of 15 knots or more below 1600 feet along the glide paths above the aerodrome, or significant low-level turbulence, which is quantified in terms of the cube root of eddy dissipation rate (EDR) following international practice. Moderate turbulence means an EDR between 0.3 and $0.5 \mathrm{~m}^{2 / 3} \mathrm{~s}^{-1}$, and severe turbulence refers to EDR above $0.5 \mathrm{~m}^{2 / 3} \mathrm{~s}^{-1}$. Windshear has been reported to occur in aircraft incidents/accidents in the other airports, such as Keller et al. [1]. In Hong Kong, lowlevel windshear/turbulence mostly occurs in the spring time when there is stable atmospheric boundary layer and in summer time when there is thunderstorm or strong southwesterly winds (e.g., strong southwest monsoon, or under the influence of tropical cyclones). Statistically, a significant windshear report is received for every 500 flights, though there may be cases with significant windshear encountered but without reporting to the air traffic control. About $70 \%$ of the reports are due to terrain-disrupted airflow when wind is blowing from east through southeast to southwest. About $20 \%$ of the reports are due to sea breeze (with possibly wind direction shear). The remaining reports are due to thunderstorms, low-level jets, and so forth.

Apart from terrain-disrupted airflow, thunderstorms at the airport can also bring about significant windshear to the airport. The most severe form of windshear is microburst, which means low-level headwind loss of 30 knots or more, for example, in precipitation as detected by a radar. 
However, besides thunderstorms, terrain-disrupted airflow can also bring about microburst, called the terrain-induced microburst, if the headwind loss is found to reach 30 knots or more and in rain, for example, in tropical cyclone or southwest monsoon situation. One case of terrain-induced microburst has been documented in Shun and Lau [2], which discusses terrain-induced microburst in neutral atmospheric condition as associated with the strong winds of a tropical cyclone. In the present paper, this kind of microburst in southwest monsoon is considered, but in terms of prevailing wind flow, atmospheric boundary layer structure, and the orientation/location of terrain-induced microburst, the two cases are rather similar.

In order to monitor low-level windshear and turbulence at HKIA, the Hong Kong Observatory (HKO) operates a suite of meteorological equipment at the airport area. A Terminal Doppler Weather Radar (TDWR) has been running to the northeast of the airport to monitor the change of radial velocity in rain. Since the radar beam is oriented along the runway, the radial velocity change may be taken as a headwind/tailwind change. It is a $\mathrm{C}$ band area with significant sidelobe depression, so that it could be used to measure rain drop return signals close to the sea and land surfaces. In nonrainy weather conditions, the Doppler Light Detection and Ranging (LIDAR) systems could be used for windshear and turbulence detection. There are two LIDAR systems running at HKIA, each serving a particular runway of the airport. A laser beam with a wavelength of about 2 microns is used, and dust and aerosols in the air are tracked in order to measure the wind. The TDWR and LIDAR systems are used for real-time detection of low-level windshear and turbulence. Their technical details and applications could be found in Shun and Johnson [3] and Shun and Chan [4], respectively. Observations of terrain-disrupted airflow in other areas of complex terrain could be found in the literature, for example, Mobbs et al. [5].

Apart from detection-based service, the Observatory also attempts to forecast the changes in low-level wind. In particular, an aviation model (AVM), based on Weather Forecast and Research (WRF) model [6], has been running for the airport area with a spatial resolution down to $200 \mathrm{~m}$. The output wind data are ingested into the LIDAR windshear alerting algorithm, also called the glide-path scan windshear alerting algorithm (GLYGA) to forecast the occurrence of low-level windshear. The low-level turbulence is predicted by directly outputting the forecast EDR based on the large eddy simulation (LES) boundary layer parameterization scheme. The model has been found to be successful in predicting terrain-disrupted airflow in stable boundary layer, including Foehn wind and mountain wave. The configuration of AVM and its application for stable boundary layer flow could be found in Chan and Hon [7]. An account of the earlier version of the model is given in Wong et al. [8]. Lee waves in other areas of complex terrain and the forecast of such waves could be found in Vosper et al. [9]. Terrain-induced windshear has been studied for other airports using high resolution numerical model, for example, in Boilley and Mahfouf [10]. Orographic effects (i.e., valley breezes and hill effects) are simulated very well in the high resolution model and could lead to a better prediction of vertical windshear or local turbulence

In this paper, a number of new applications of AVM are described. It is used for a case without temperature inversions in the boundary layer basically in the summer time of southern China, to see its performance in predicting the terrain-disrupted airflow and thus low-level windshear and turbulence that would be crucial to the operating aircraft at HKIA. Also, this is the first time that terrain-induced microburst is forecast, and the structure of this kind of microburst is studied in slightly greater depth by looking at the vertical cross section of the model simulated wind field. It is hoped that the paper would be a useful reference for other airports in which terrain-disrupted airflow would be one crucial factor in their operations, particularly about the detection and forecasting of the windshear and turbulence, under similar atmospheric conditions. It is noted that this paper only discusses one kind of low-level windshear associated with terrain-disrupted airflow, namely, boundary layer without temperature inversion in the summer time, which is rather typical. Windshear can also occur in Hong Kong International Airport (and in fact far more frequent) in spring time in the presence of temperature inversions inside the atmospheric boundary layer.

The boundary layer in Hong Kong mostly has a height of about 1 to $2 \mathrm{~km}$ above ground. It may be determined from the occurrence of temperature inversion in the radiosonde data, for example, trade wind inversion. In the spring time, there can be temperature inversion associated with the cooler continental airmass near the surface undercutting the warmer maritime airmass aloft. The heights of such inversions can be in the order of $1 \mathrm{~km}$ above sea/land surface. In the previous papers (e.g., Chan and Hon [7]), terrain-disrupted airflow occurs with the appearance of temperature inversion within the boundary layer. This paper will discuss terrain-disrupted airflow without the presence of temperature inversion inside the atmospheric boundary layer. This kind of situation may occur in summer time and can be rather typical under the influence of strong southwest monsoon.

\section{Background Meteorological Condition}

The surface isobaric chart at 00 UTC of the day, namely, 21 July 2015, is shown in Figure 1. There is surface trough of low pressure over inland areas of southern China. Along the coast, the strong southwest monsoon is prevailing, which could favour the occurrence of terrain-disrupted airflow at HKIA.

The upper air meteorological condition may be revealed by the upper air ascent (radiosonde) launched at King's Park, which is located at about $20 \mathrm{~km}$ to the east of the airport at 00 UTC of the day. The vertical profiles of the weather elements can be found in Figure 2. It could be seen that the winds below $2000 \mathrm{~m}$ amsl are basically southwesterly. The wind speed profile suggests that, between $600 \mathrm{~m}$ and $1700 \mathrm{~m}$ amsl, there is a band with wind speed greater than $20 \mathrm{~m} / \mathrm{s}$. As a result, strong southwesterly winds prevailed in the southern China region. The temperature and humidity profiles are also given in Figure 2, together with the potential temperature 


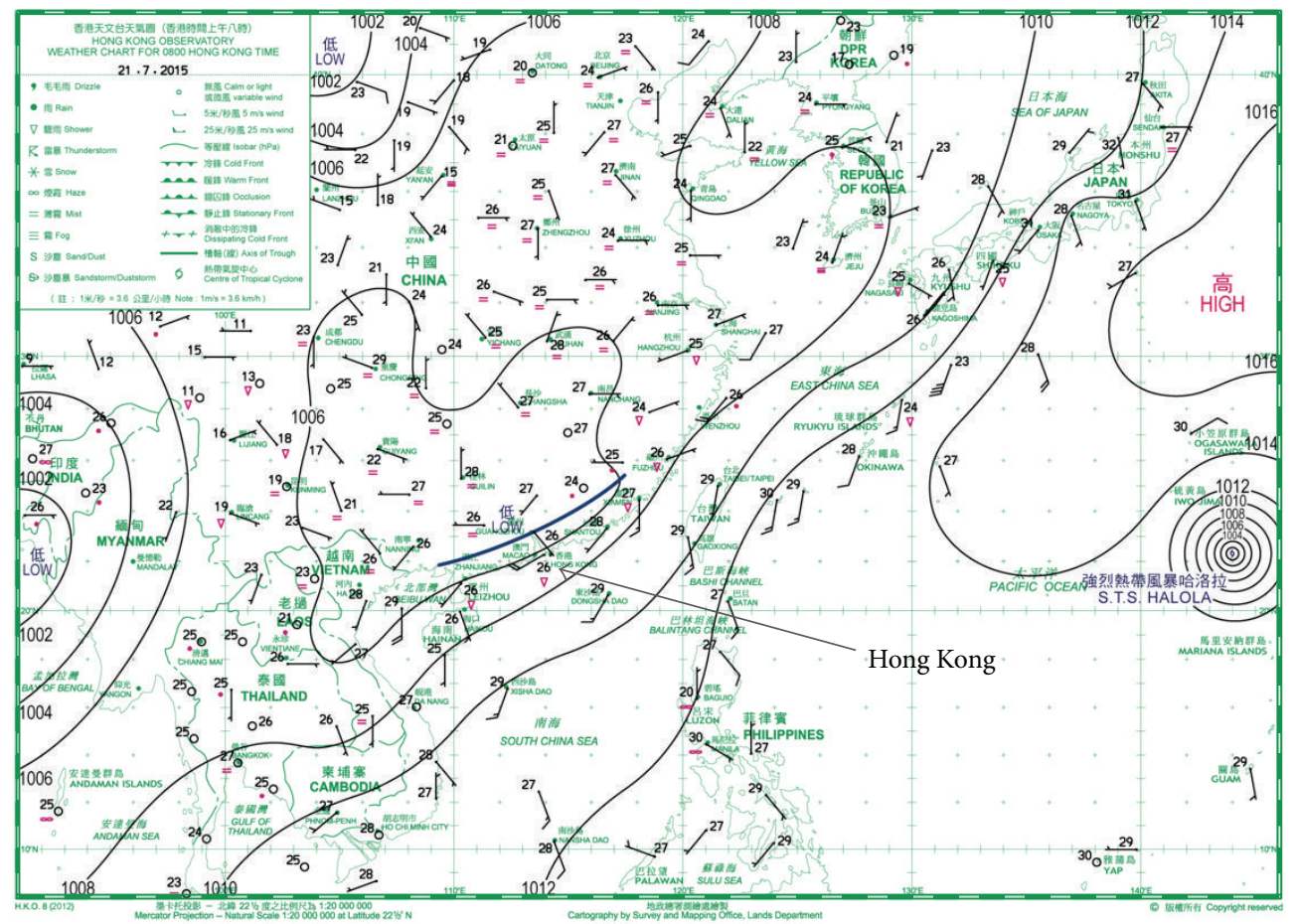

FIgURE 1: The surface isobaric chart at 00 UTC, 21 January 2015.

profile with the calculated Brunt-Vaisala frequency $(N)$ and cross-mountain wind speed $(U)$. The atmosphere is basically saturated within the boundary layer. No temperature inversion could be identified.

\section{Terrain-Induced Microburst Case}

The TDWR sounds out microburst alert (MBA) in the early morning of 21 July 2015. A sample radial velocity plot from the TDWR at that time could be found in Figure 3(a). It could be seen that the background flow is strong southwesterly, with the winds blowing towards the radar. Downstream of the Lantau terrain, there are a number of streaks (narrow, elongated areas) of higher wind speeds and lower wind speeds, which are highlighted in Figure 3(a). At a streak of higher wind speed downstream of Siu Ho Wan (location in Figure 3(a)), it is connected with an area of lower wind speed just emerging from the terrain. The existence of an area of higher southwesterly wind and another area with much lower wind speed in proximity results in a microburst alert, because the radial velocity change reaches 30 knots or more in rain.

To study the wind streaks in greater detail, vertical cross sections are made in Figure 3(a). Firstly, it could be seen from Figure 3(a) that the higher wind streaks are associated with lower land over Lantau Island (i.e., $1^{\prime}, 3^{\prime}, 5^{\prime}$, and $7^{\prime}$ associated with $1,3,5$, and 7 ), and lower wind streams are associated with higher land over Lantau Island (i.e., $2^{\prime}, 4^{\prime}$, and $6^{\prime}$ are associated with 2,4 , and 6). The vertical cross section $A B$ is shown in Figure 3(b). At the higher surface wind speed, the jet core is lower as shown in 1,3 , and 5 . On the other hand, for lower surface wind speed, the jet core is higher, as shown in 2 and 4 , due to obstruction of the terrain. This point is confirmed by the vertical cross sections in Figures 3 (c) and 3(d). In Figure 3(c), the jet core is about 700 to $800 \mathrm{~m}$ above sea surface. In Figure 3(d), the jet core is about 300 to $400 \mathrm{~m}$ above sea surface. The southwesterly wind streaks in this case are mainly due to effect of the terrain on the strong background southwest monsoon.

The Graphical Situation Display (GSD) of the Observatory's Windshear and Turbulence Warning System, which summarizes the windshear and turbulence alerts in force in real time, is shown in Figure 4. The MBA area is oriented north-northeast to south-southwest, just downstream of Siu Ho Wan, and alerts (headwind loss of 40 knots) are in force for the runway corridors to the east of the southern runway of HKIA. This MBA is similar to the one documented in Shun and Lau [2].

The forecast surface wind from AVM is examined at that time to see if there is any signature of terrain-induced MBA in the model simulation. The 7-hour forecast of surface wind based on the model run at 14 UTC, 20 July 2015, is shown in Figure 5. It could be seen that the winds are rather light over the valley just upstream of Siu Ho Wan. The winds then turn to southwesterly after leaving this valley, and there is strong southwesterly generally prevailing over the runway corridors (within the square boxes, which are alert areas for windshear/turbulence). This distribution of wind speed is generally consistent with that given by the TDWR, and it results in the occurrence of an area of "terrain-induced MBA" in the model simulation. Similar change of the wind speed and wind direction could be found in other valleys and the adjacent runway areas, such as the region around Tung Chung 


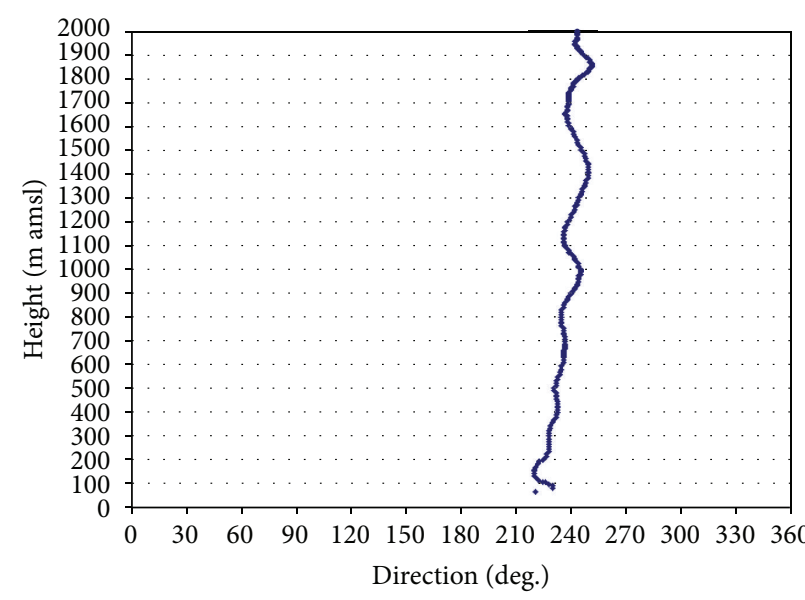

(a)

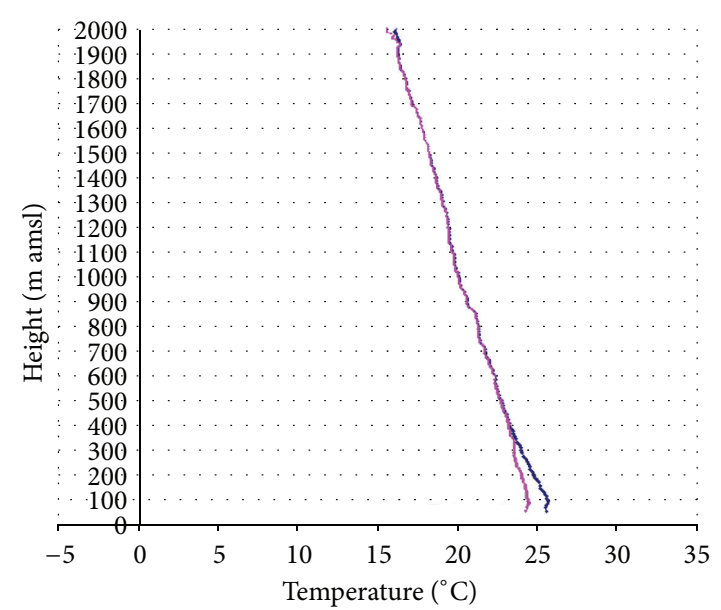

- Temperature

- Dew point

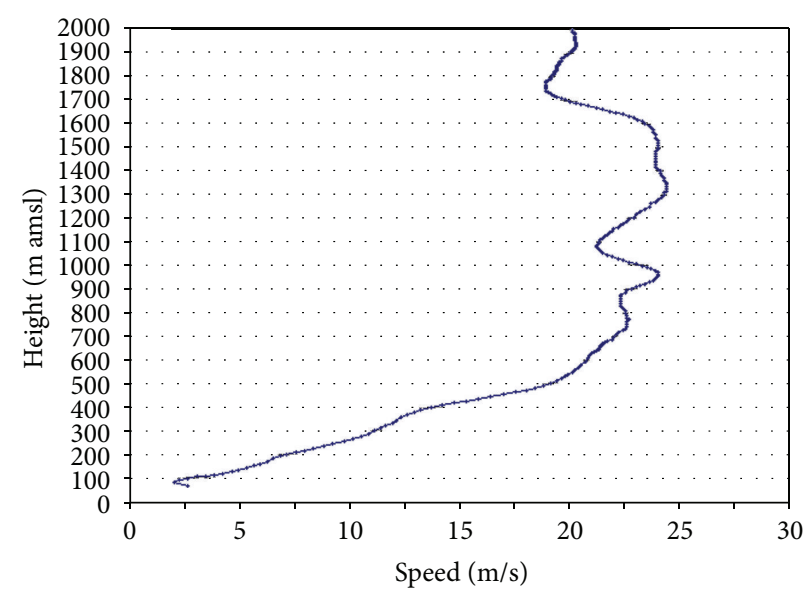

(b)

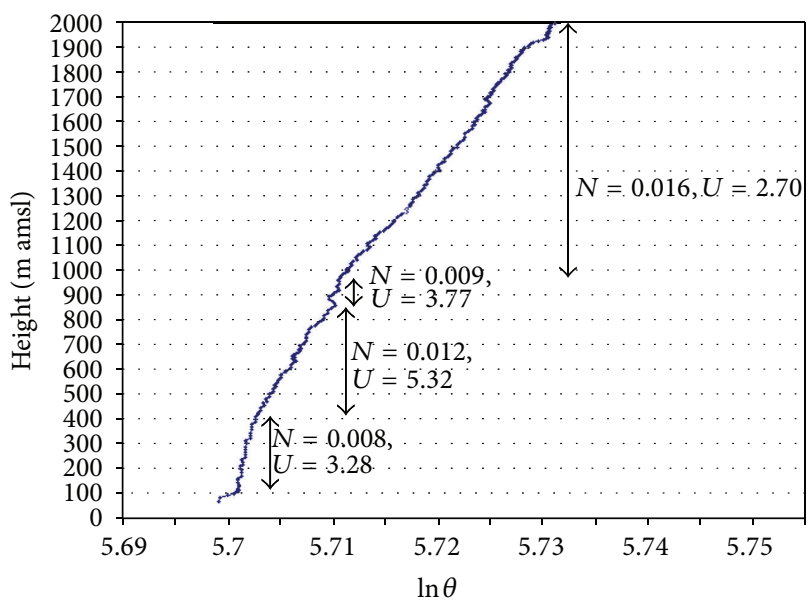

(d)

FIgure 2: The radiosonde ascent data at King's Park at 00 UTC, 21 July 2015: (a) wind direction, (b) wind speed, (c) temperature (blue) and dew point (pink), and (d) potential temperature.

(location in Figure 5), though the radial velocity change is smaller and thus MBA has not been triggered by the TDWR.

The simulation of the existence of the terrain-induced MBA by AVM allows the possibility of studying the wind structure of the MBA in greater detail. A vertical cross section is made as in Figure 5, and it is shown in Figure 6. It is not in the orientation of the measurement radials of the TDWR but is taken to be along the maximum change of wind speed from the valley at Siu Ho Wan to the sea and higher surface wind speed area to the north. Figure 6(a) shows the north-south component of the wind, and Figure 6(b) shows the wind speed distribution. It could be seen that the two distributions are very similar, and thus the north-south component of the wind makes a significant contribution to the wind speed distribution. In general, the wind speeds are higher over the mountain top as expected, with the jet core at a height of about 400 to $500 \mathrm{~m}$ above the local terrain. However, downstream of the mountains over the airport area, there is a similar high speed region over the sea surface.
This appears to be related to the downward transport of the horizontal momentum in the downslope wind. In fact, significant downward motion is simulated down the hill in the vertical velocity plot at Figure 6(c). This core of higher wind speed, together with the generally lighter winds inside the valley, contributes to the occurrence of terrain-induced MBA. It is interesting to note from Figure 6(c) that there appears to be a wave also between 1200 and $2000 \mathrm{~m}$ above the area of higher wind speed over the airport area. The physical significance of this wave is yet to be studied.

\section{Fluctuating Headwind and Low-Level Turbulence}

Apart from terrain-induced MBA, there are also fluctuations in the headwind profile along the runway and its extended centerline, so that the aircraft may experience low-level windshear. Such a case occurs at about 03:20 UTC, 21 July 2015. There was an aircraft landing at the north runway from 


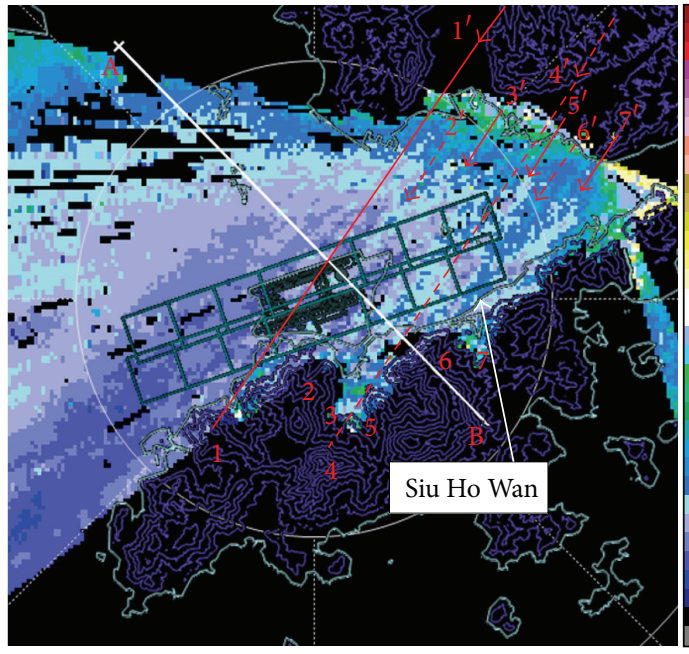

(a)

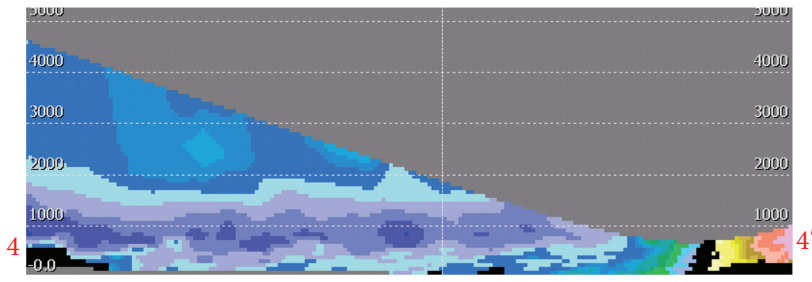

(c)

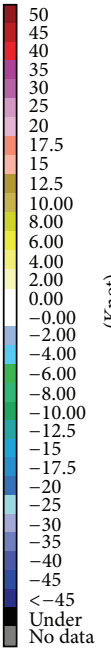

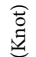

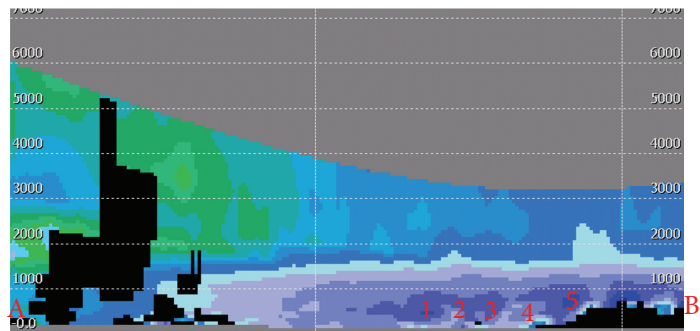

(b)

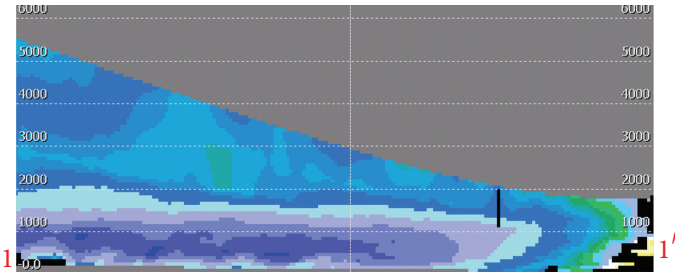

(d)

FIGURE 3: The TDWR radial velocity plot at 0.6-degree conical scan at the time of terrain-induced microburst, that is, 05:36:24 a.m. of 21 July 2015. Higher wind speed streaks are indicated by solid red arrows, and lower wind speed streaks are indicated by dashed red arrows. The time displayed is in Hong Kong time (UTC +8 hours). The vertical cross sections AB, $4-4^{\prime}$ and $1-1^{\prime}$, are shown in (b), (c), and (d), respectively.

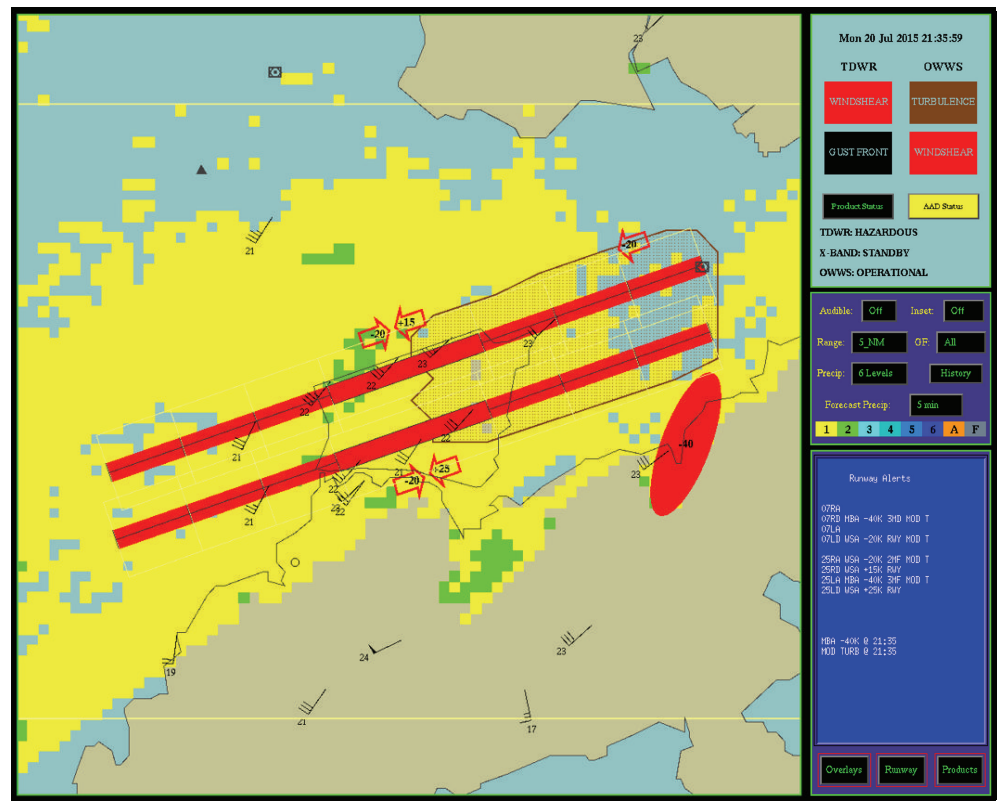

FIgURE 4: The GSD display at the time of terrain-induced microburst, which is given as a red ellipse. The arrows are the windshear alerts provided by LIDAR, and the brown, dotted area is the turbulence alerting area. The background yellow/green is the TDWR radar reflectivity as expressed as the intensity level of precipitation. The time displayed is in UTC. The -40 knots microburst area (solid red ellipse) just touches upon the 3-nautical-mile ARENA box (white) to the east of the south runway. 


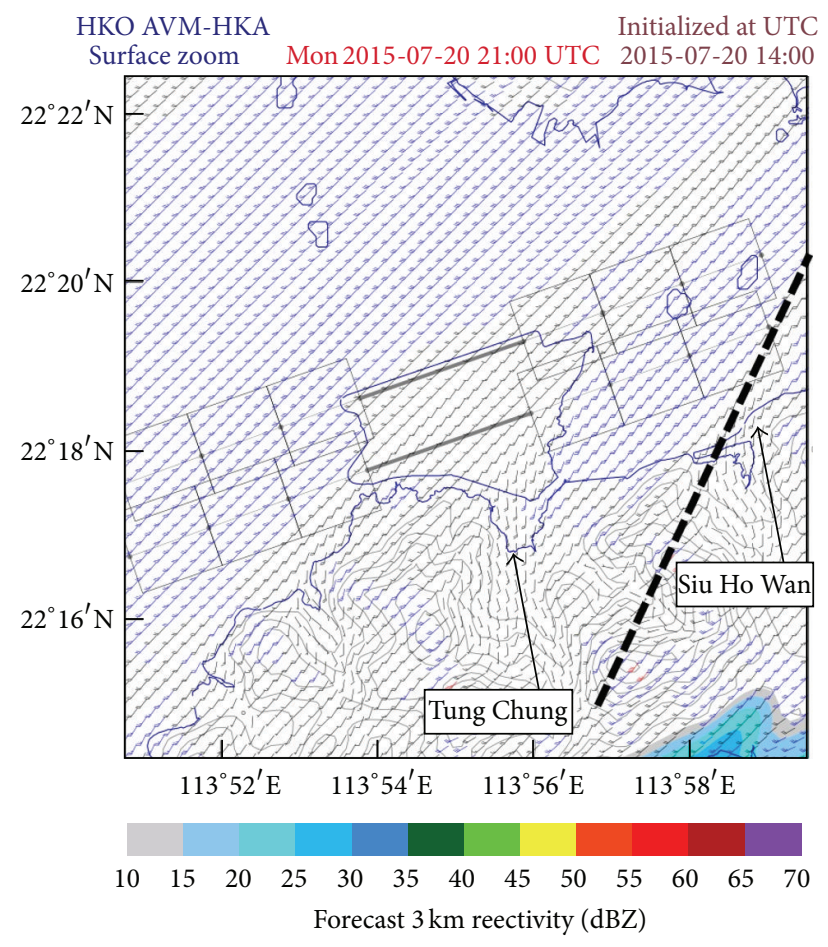

FIGURE 5: The forecast surface wind by AVM at 21 UTC, 20 July 2015, for the model run initialized at 14 UTC, 20 July 2015. The boxes on the two sides of each runway are the locations at 1,2, and 3 nautical miles away from the runway end. The location of the vertical cross section of Figure 6 is shown as a dotted line. Height contours are in $100 \mathrm{~m}$.

the east (i.e., 25RA runway corridor) experienced headwind loss of 15 knots at a height of about 300 to 400 feet. This headwind loss is successfully captured by GLYGA based on the wind data from the north-runway LIDAR, as shown in Figure 7. In general, the headwind profile takes on a shape of a rotated "S."

In order to see the performance of AVM in this windshear case, the AVM-simulated GLYGA at 04 UTC, 21 July 2015, based on the forecast initialized at 00 UTC, 21 July 2015, is given in Figure 8. It could be seen that AVM-GLYGA forecast the occurrence of terrain-induced windshear over a number of runway corridors. In particular, over 25RA, the headwind profile also takes on the shape of a rotated "S," though the headwind change is less abrupt and occurs over a longer distance as compared with the actual LIDAR observations in Figure 7. Nonetheless, AVM appears to have the skill of forecasting terrain-induced windshear several hours ahead even in a case without temperature inversions inside the boundary layer of the atmosphere.

The simulated surface wind by AVM is shown in Figure 9. It could be seen that the surface winds are rather uniform, which is consistent with the actual observations (not shown). As a result, just based on the surface winds only, the low-level windshear is not noticeable. This points to the importance of measuring upper air winds within the boundary layer using remote-sensing technique, such as a Doppler LIDAR.

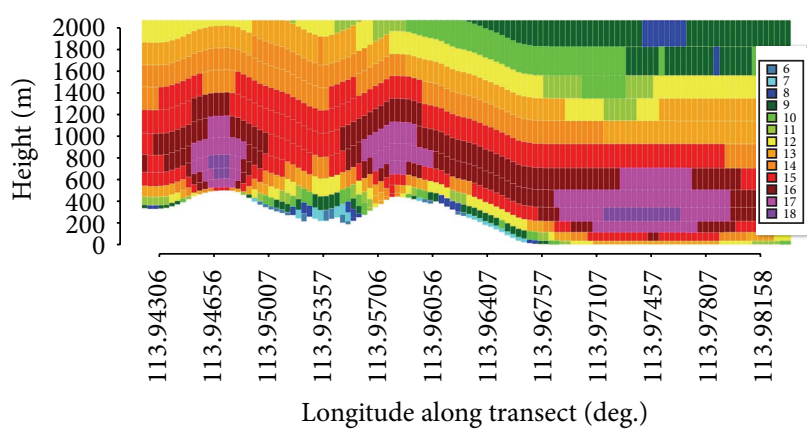

(a)

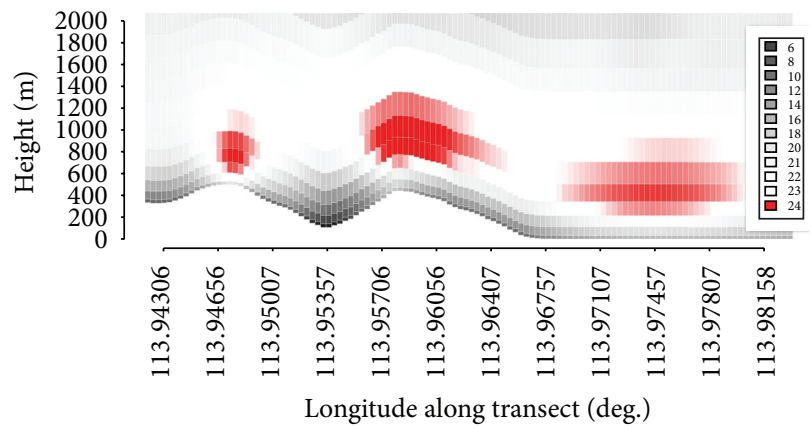

(b)

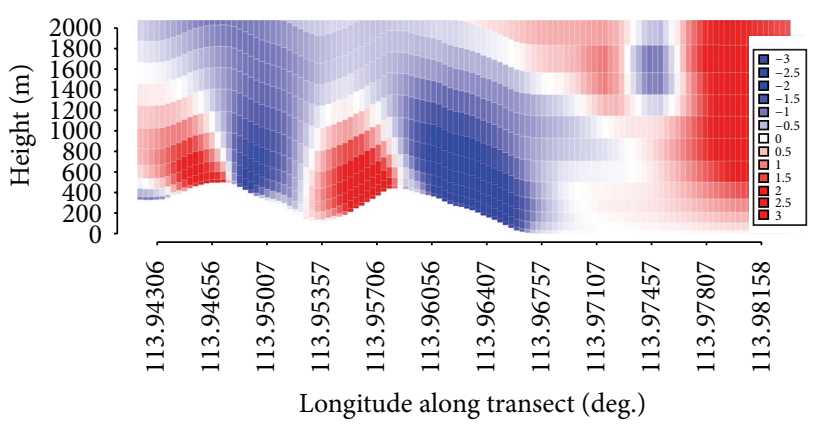

(c)

FIgURE 6: The vertical cross section (along the line given in Figure 5): (a) the north-south component of the wind, (b) the wind speed, and (c) the vertical velocity.

The vertical cross section across the eastern approach to the north runway is shown in Figure 10. The wind speed distribution is shown in this figure. It could be seen that, for the higher headwind at about 1 nautical mile away from the runway end (eastern end of the north runway), there is a lowlevel jet in the southwesterly wind. Such information is not obtained from the LIDAR in the present scanning strategy (because there is no Range Height Indicator scan along that direction). It can be depicted with the high resolution numerical weather prediction model.

Apart from low-level windshear, moderate turbulence was also experienced by an aircraft at 25RA at 03:07 UTC, 21 July 2015. EDR map is also generated in real time based on LIDAR data [11], and it is given in Figure 11. The formulation of LIDAR-based EDR calculation could be found in the pioneering work of Frehlich et al. [12]. Though the range of 

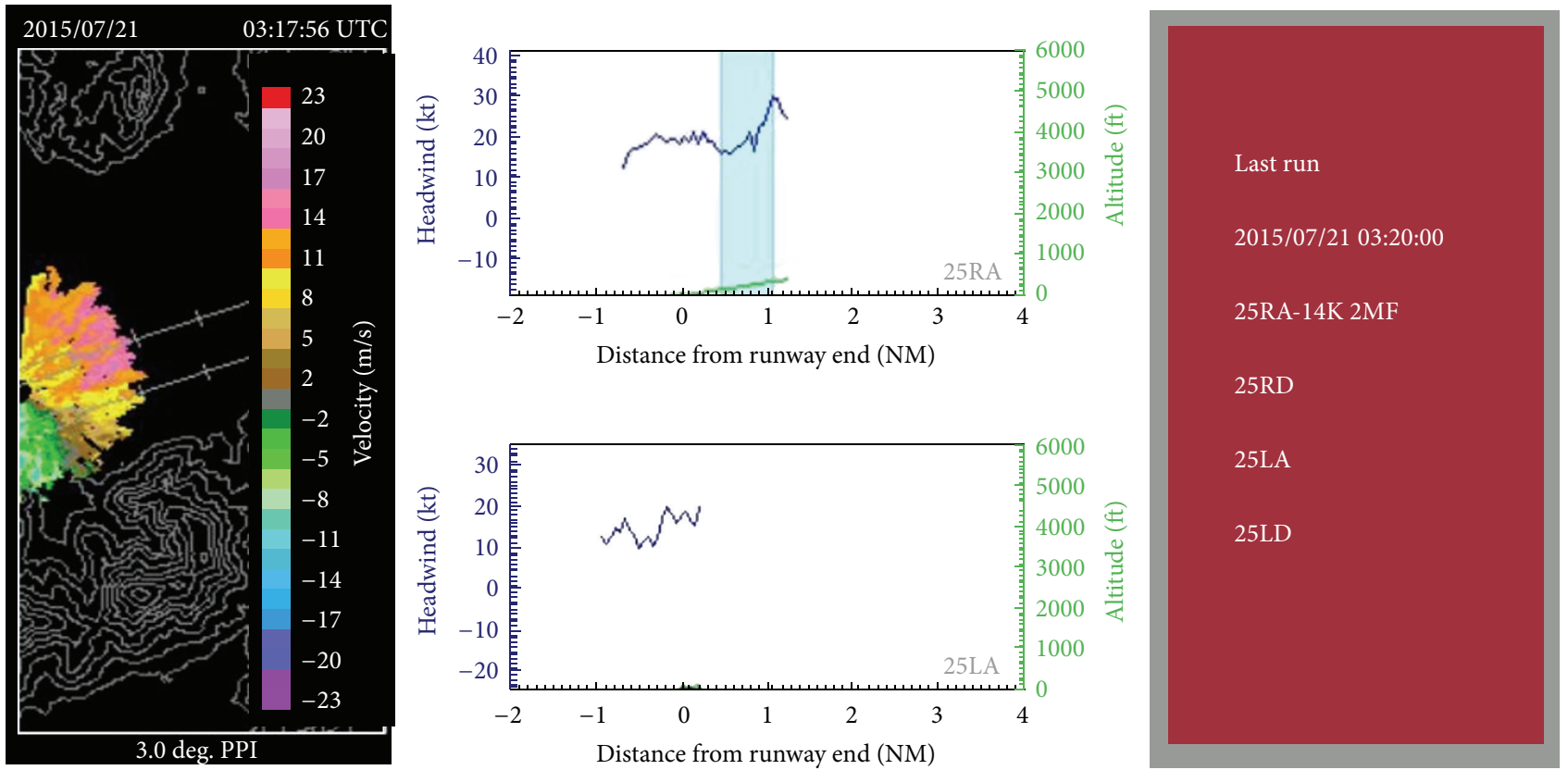

Figure 7: The GLYGA display at the time of low-level windshear. The left hand side is the 3-degree conical scan of radial velocity of the LIDAR, and the curves in the middle are the headwind profiles (headwind refers to the landing direction of the aircraft in the respective runway). The significant windshear is highlighted in a blue block.
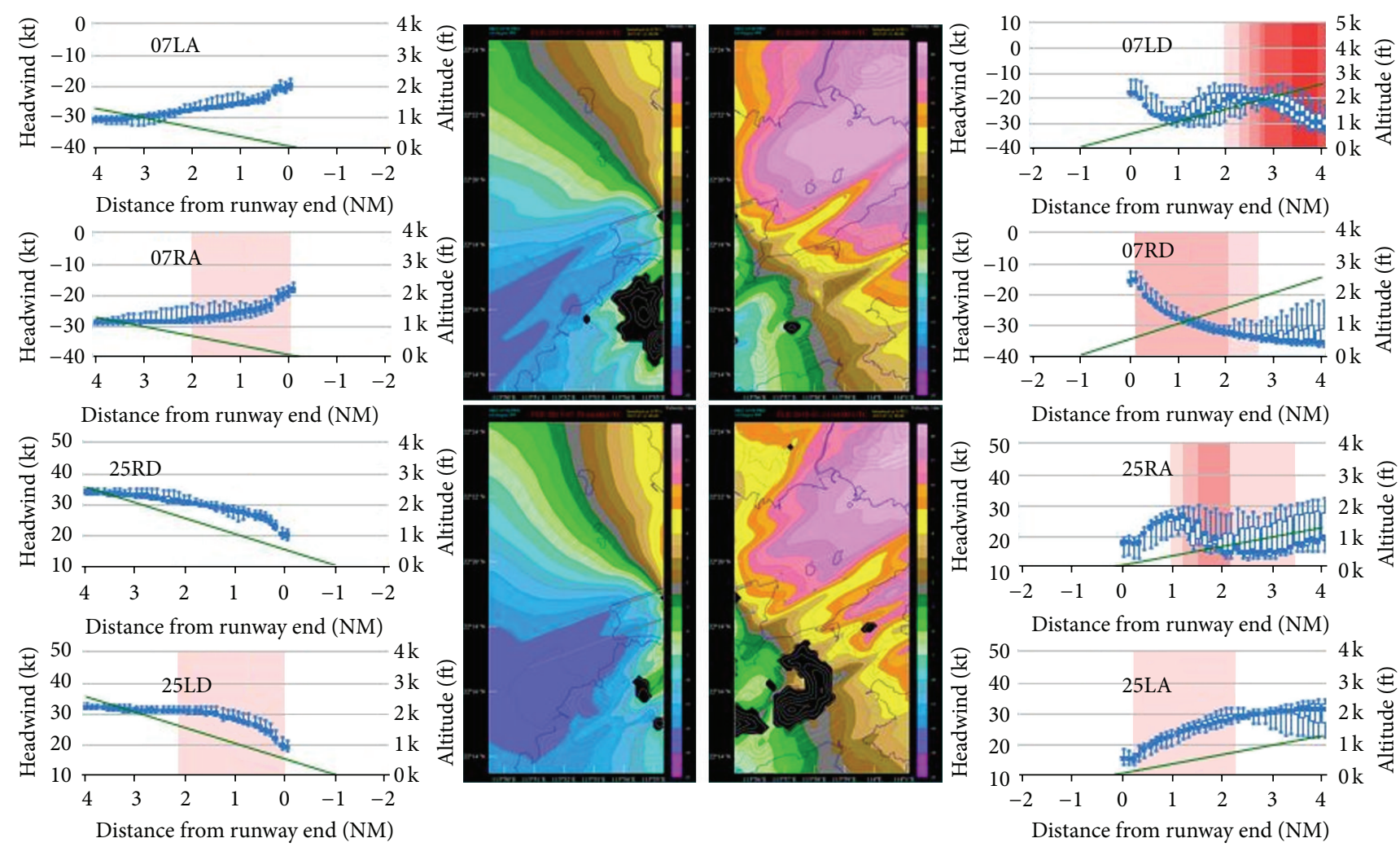

Distance from runway end (NM)
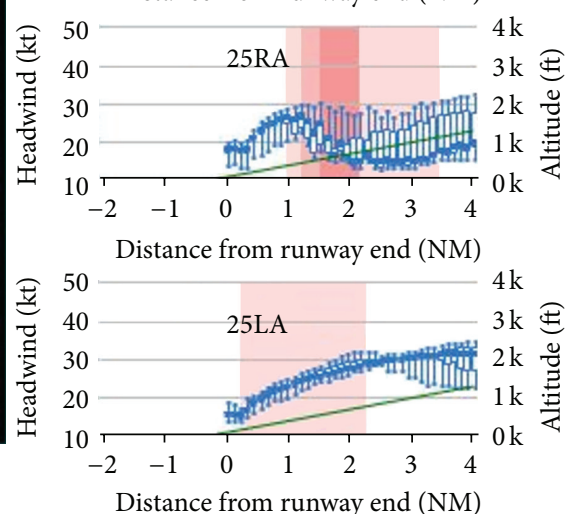

FIgURE 8: The AVM-GLYGA display. The simulated LIDAR radial velocities are given in the middle. This simulated LIDAR velocity image may be compared with the Plan Position Indicator (PPI) image from the real LIDAR in the left hand side of Figure 7. The forecast headwind profiles (blue) and detected windshear locations (red blocks) are given on the two sides. 


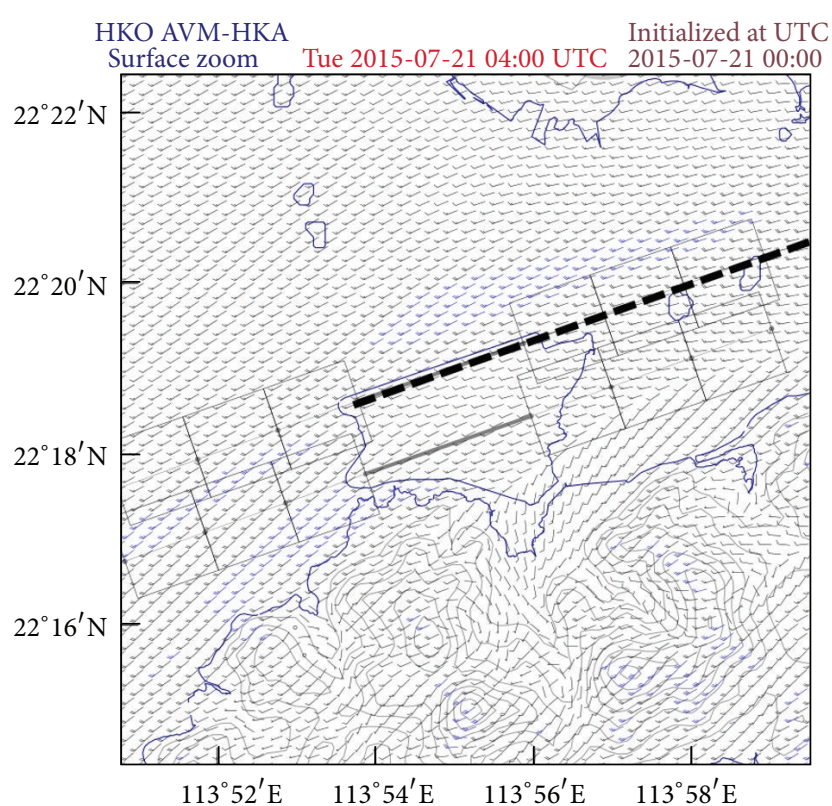

FIGURE 9: The simulated surface wind at the time 04 UTC, 21 July 2015, for the model run initialized at 00 UTC, 21 July 2015 . The boxes on the two sides of each runway are the locations at 1,2 , and 3 nautical miles away from the runway end. The vertical cross section of Figure 10 is shown as a dotted line.

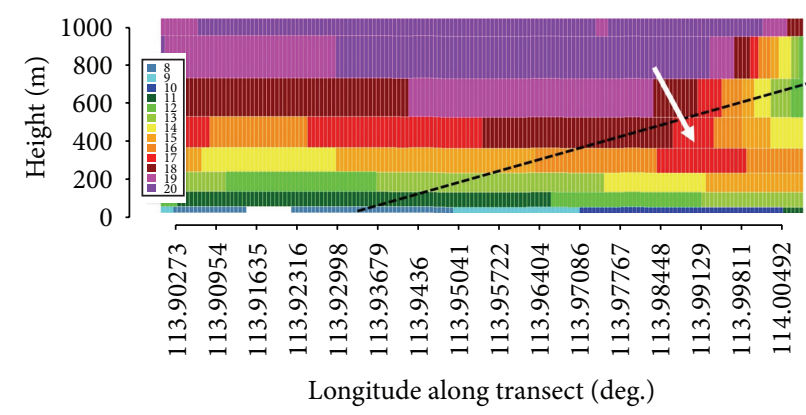

FIGURE 10: The vertical cross section of wind speed along the dotted line as shown in Figure 9. The descending of a jet is indicated by a white arrow.

the LIDAR is rather limited on that day due to high humidity near the surface, it could be roughly seen that moderate turbulence could be expected over 25RA runway corridor. The corresponding TDWR velocity image (not shown) is similar to that shown in Figure 3(a), but the wind speed is generally lower. The AVM-forecast EDR map at 3-degree conical scan is shown in Figure 12. The generation of this kind of map based on NWP output has been described in Chan [13]. It is able to capture the occurrence of low-level moderate turbulence, and the spatial distributions of EDR in Figures 11 and 12 appear to be rather similar.

\section{Conclusions}

Two cases of terrain-induced windshear at HKIA have been studied in depth in this paper. In particular, this is the first

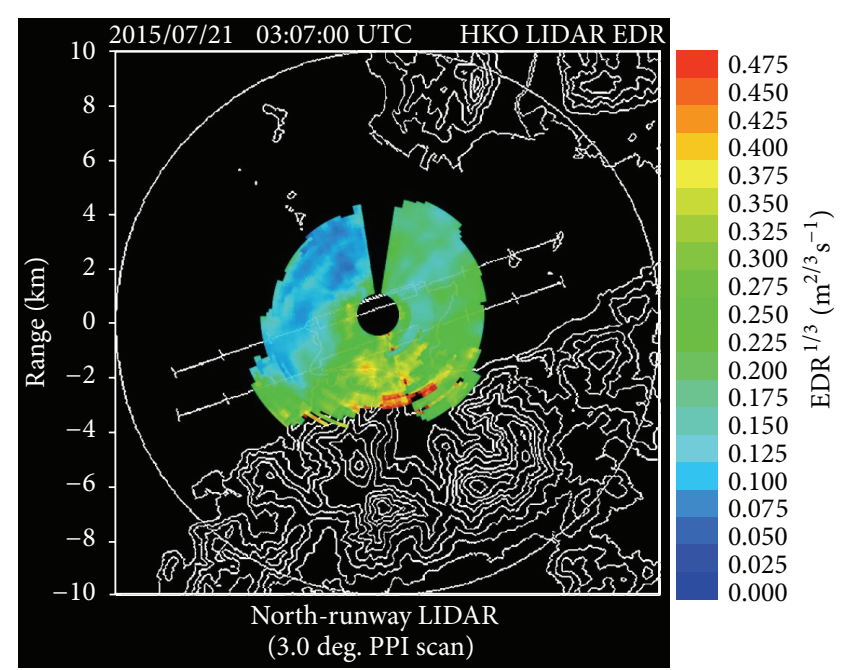

FIGURE 11: The LIDAR-determined EDR map at 03:07 UTC, 21 July 2015. The scale of $\mathrm{EDR}^{1 / 3}$ is shown on the right hand side.

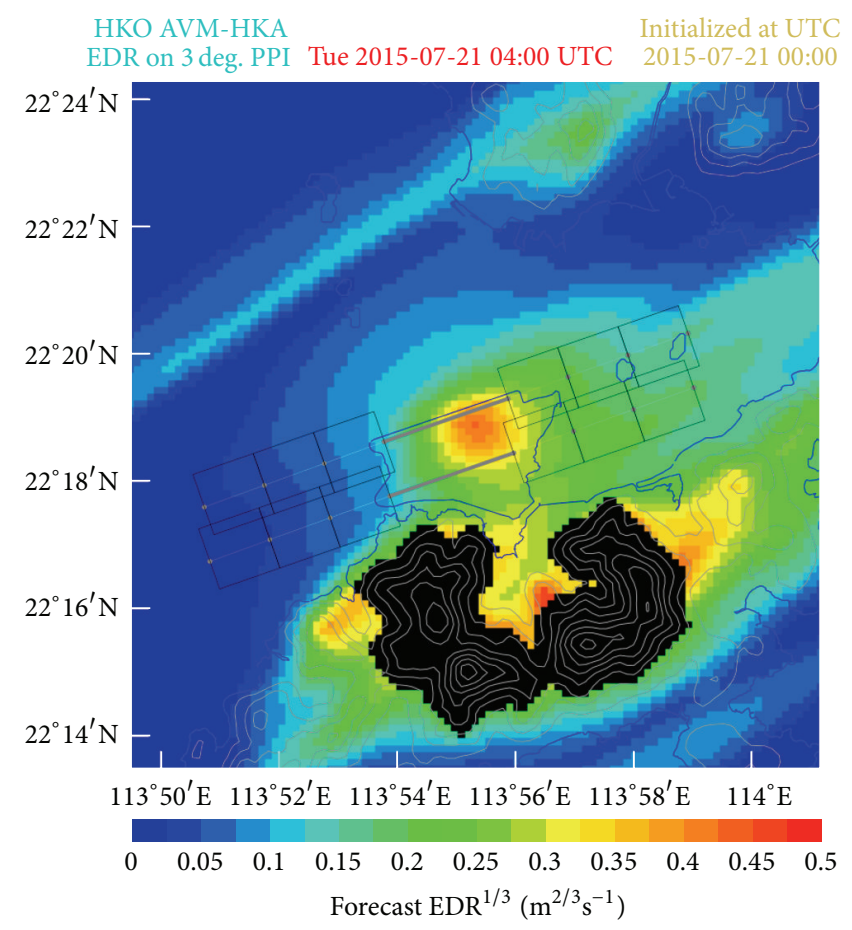

FIgURE 12: The simulated EDR map for 3-degree conical scan of the LIDAR.

time that simulation of terrain-induced microburst is studied for Hong Kong. Also, the windshear cases occur at a time without temperature inversion in the thermodynamic profile, and the performance of a high resolution numerical model in such conditions is examined. The model is found to reproduce the windshear features quite well. It also offers other data (such as vertical velocity and vertical cross section across the windshear features) that provide further information about the airflow. 
The performance of AVM in other kinds of windshear at HKIA would be studied in the future. In particular, the application value of AVM-GLYGA would be studied more comprehensively using a larger database of pilot windshear reports.

\section{Conflict of Interests}

The authors declare that there is no conflict of interests regarding the publication of this paper.

\section{References}

[1] T. L. Keller, S. B. Trier, W. D. Hall, R. D. Sharman, M. Xu, and Y. Liu, "Lee waves associated with a commercial jetliner accident at Denver International Airport," Journal of Applied Meteorology and Climatology, vol. 54, no. 7, pp. 1373-1392, 2015.

[2] C. M. Shun and S. S. Y. Lau, “Terminal Doppler Weather Radar (TDWR) observation of atmospheric flow over complex terrain during tropical cyclone passages," in Microwave Remote Sensing of the Atmosphere and Environment II, vol. 4152 of Proceedings of SPIE, Sendai, Japan, December 2000.

[3] C. M. Shun and D. B. Johnson, "Implementation of a terminal Doppler weather radar for the new Hong Kong international airport at Chek Lap Kok," in Proceedings of the 6th Conference on Aviation Weather Systems, Dallas, Tex, USA, January 1995.

[4] C. M. Shun and P. W. Chan, "Applications of an infrared Doppler lidar in detection of wind shear," Journal of Atmospheric and Oceanic Technology, vol. 25, no. 5, pp. 637-655, 2008.

[5] S. D. Mobbs, S. B. Vosper, P. F. Sheridan et al., "Observations of downslope winds and rotors in the Falkland Islands," Quarterly Journal of the Royal Meteorological Society, vol. 131, no. 605, pp. 329-351, 2005.

[6] W. C. Skamarock, J. B. Klemp, J. Dudhia et al., "A description of the advanced research WRF version 2," NCAR Tech Notes 468+STR, 2005.

[7] P. W. Chan and K. K. Hon, "Performance of super high resolution numerical weather prediction model in forecasting terraindisrupted airflow at the Hong Kong International Airport: case studies," Meteorological Applications, vol. 23, no. 1, pp. 101-114, 2016.

[8] W.-K. Wong, C.-S. Lau, and P.-W. Chan, "Aviation model: a fine-scale numerical weather prediction system for aviation applications at the Hong Kong international airport," Advances in Meteorology, vol. 2013, Article ID 532475, 11 pages, 2013.

[9] S. B. Vosper, H. Wells, J. A. Sinclair, and P. F. Sheridan, "A climatology of lee waves over the UK derived from model forecasts," Meteorological Applications, vol. 20, no. 4, pp. 466481, 2013.

[10] A. Boilley and J.-F. Mahfouf, "Wind shear over the Nice Côte d'Azur airport: case studies," Natural Hazards and Earth System Sciences, vol. 13, no. 9, pp. 2223-2238, 2013.

[11] P. W. Chan, "Generation of an eddy dissipation rate map at the Hong Kong International Airport based on Doppler lidar data," Journal of Atmospheric and Oceanic Technology, vol. 28, no. 1, pp. 37-49, 2011.

[12] R. Frehlich, S. M. Hannon, and S. W. Henderson, "Coherent Doppler lidar measurements of wind field statistics," BoundaryLayer Meteorology, vol. 86, no. 2, pp. 233-256, 1998.
[13] P. W. Chan, "Atmospheric turbulence in complex terrain: verifying numerical model results with observations by remotesensing instruments," Meteorology and Atmospheric Physics, vol. 103, no. 1, pp. 145-157, 2009. 

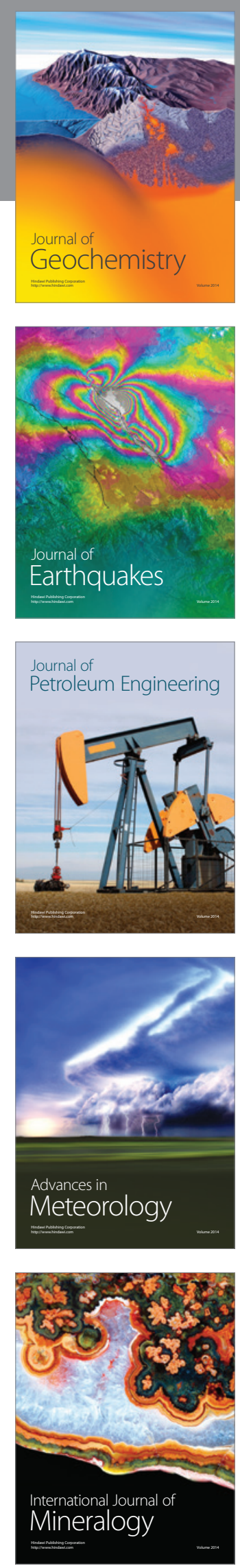
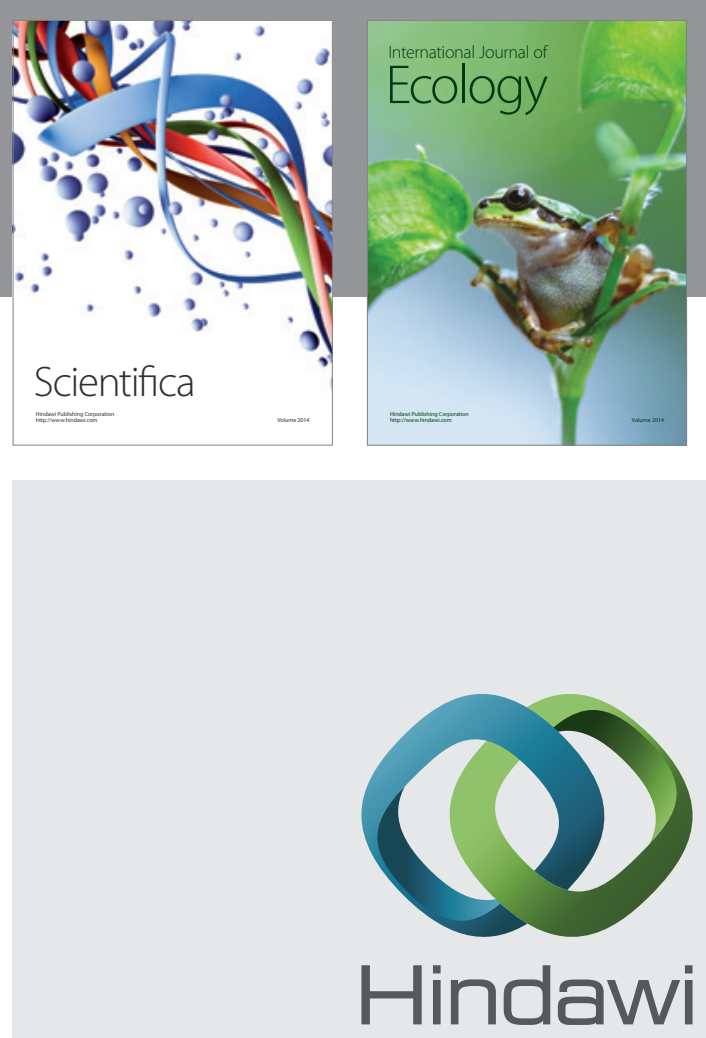

Submit your manuscripts at

http://www.hindawi.com
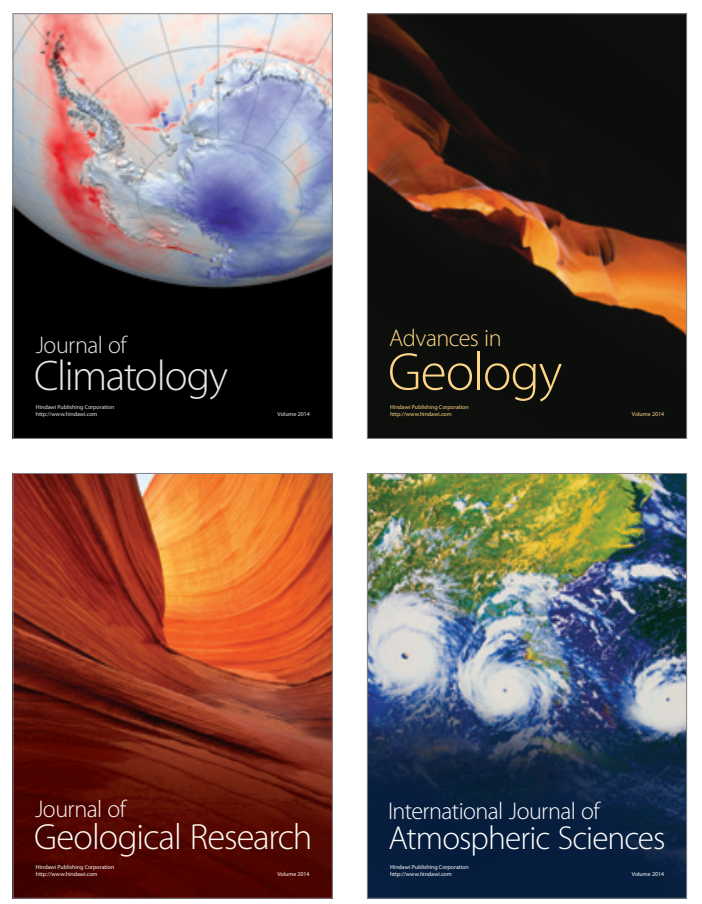

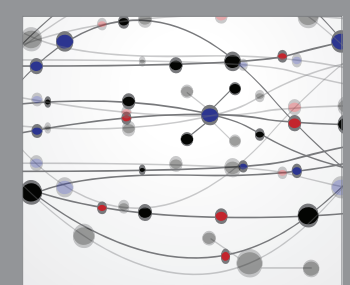

The Scientific

\section{World Journal}
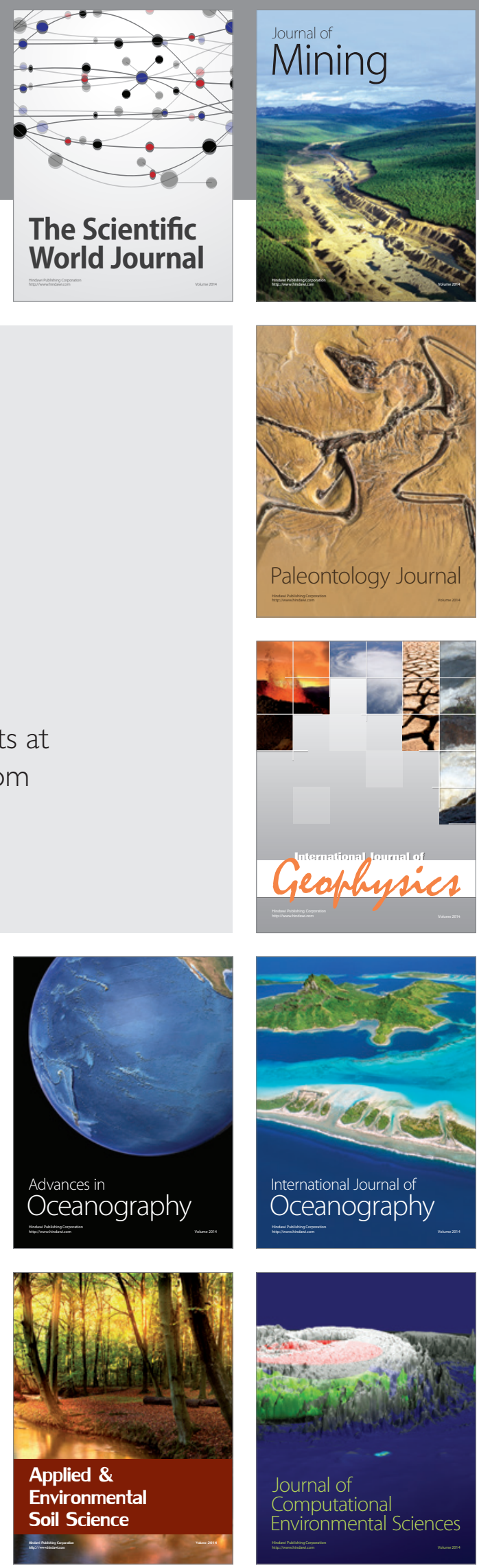